\title{
MOUNTAIN CROP GENETIC RESOURCES
}

\author{
Report of the
}

International Workshop on Mountain Agriculture

Crop Genetic Resowres

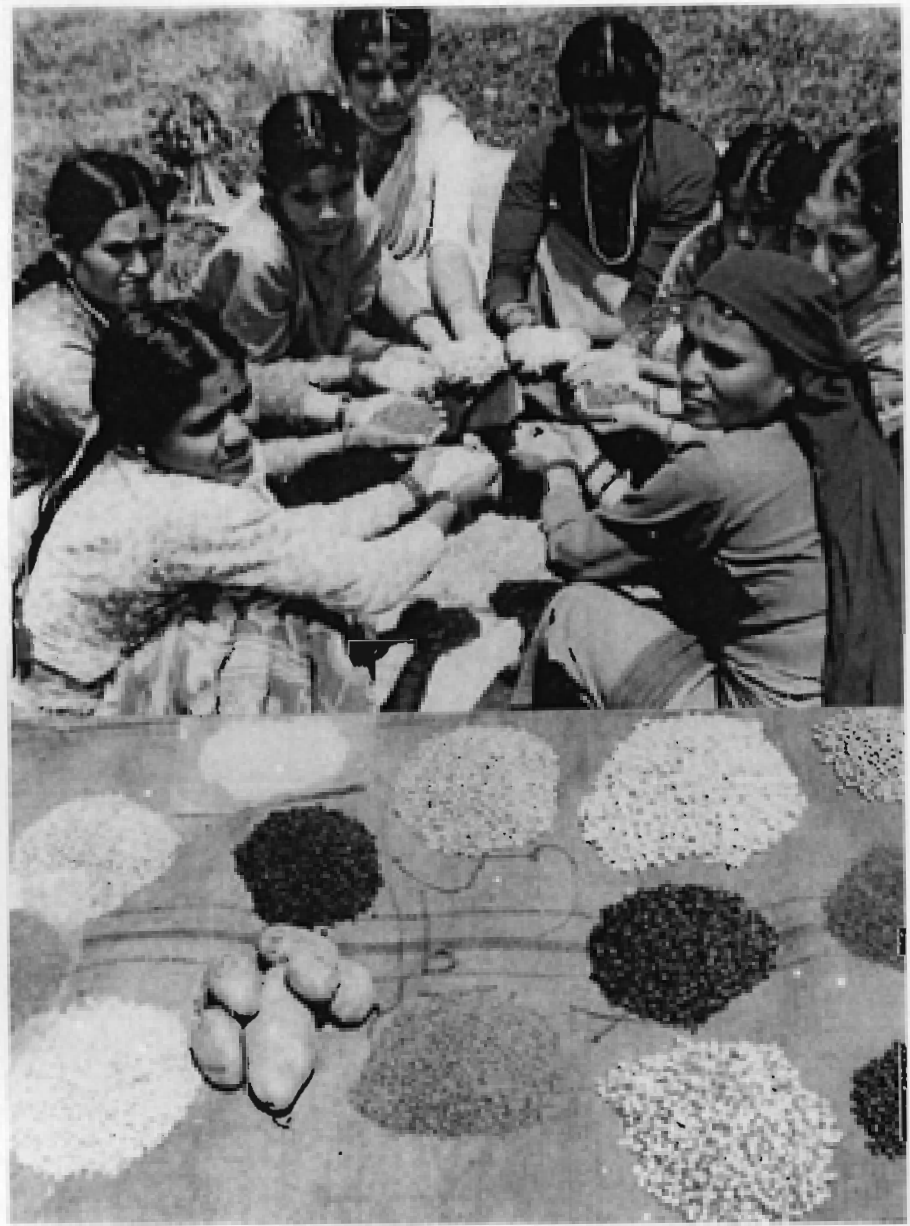

Organised by ICIMOD in collaboration with International Development Research Centre (IDRC and Ministry of Agriculture, HMG/Nepal.

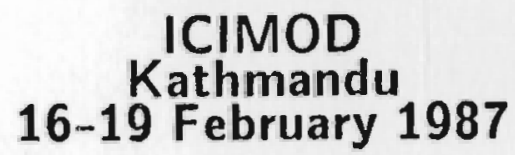


MOUNTAIN CROP GENETIC RESOURCES

Report of the

International Workshop on Mountain Agriculture and Crop Genetic Resources

International Centre for Integrated Mountain Development

Kathmandu, Nepal 


\section{Foreword}

The International Workshop on Mountain Agriculture and Crop Genetic Resources is an important component of ICIMOD programme activities on mountain agriculture which stipulates the formulation of the medium term strategy for mountain agriculture. The present international workshop was jointly organised by Ministry of Agriculture, His Majesty's Government, Nepal, International Development Research Centre (IDRC) and ICIMOD. The workshop is the first in a series of expert meetings planned for the next year or so and will lead to a major Workshop on Strategies of Mountain Agriculture: A 20-Year Perspective, to be held during 1988 at ICIMOD. The main objectives of these meetings and workshops will be to examine the strategies for striking a balance between development and environmental stability with a goal towards the attainment of longer term sustainability of mountain agriculture.

ICIMOD thanks the agriculturists and crop geneticists from the Hindu Kush-Himalaya, Andeas and the African mountain regions, who have contributed their expertise to the present workshop.

Our particular thanks are due to IDRC for their generous financial support to this workshop. Dr. Ken Riley, Programme Officer, IDRC Regional Office New Delhi, deserves special thanks for his continuing support and contribution in the design and organization of the workshop. The Ministry of Agriculture, HMG is to be specially thanked for their help in organising one-day field visit to the National Agriculture Research Centre, Khumaltar and Kakani Horticulture Farm.

It was a special pleasure to all of us that Mr. Hari Narayan Rajouria, Honourable Minister of Agriculture, inaugurated the Workshop with a stimulating inaugural address.

It is my pleasure to thank all the organizing staff of the workshop for their exceptional efforts, and particularly to Dr. Ram P. Yadav, Dr. Prodipto Roy, Dr. P.L. Maharjan and Dr. Binayak Bhadra, the latter specially for the preparation of this Workshop Report. 


\section{WORKSHOP DISCUSSIONS}

A. Physical Environment and Mountain Farming Systems

(a) Hindu Kush-Himalaya Region 4

(b) The Andean Mountain Region 7

(c) West Asia, North and Tropical African Mountain Regions

B. Genetic Resources of Mountain Crops 10

(a) Cereal Crops 12

(b) Tuber Crops 15

(c) Fruits and Medicinal Plants 16

CONCLUSIONS AND RECOMMENDATIONS 18

(a) Discussion of Group A on Mountain Farming
Systems

(b) Discussion of Group B on Crop Genetic Resources

SUMMARY OF RECOMMENDATIONS 25

$\begin{array}{lll}\text { ANNEX I Workshop Programme } & 27\end{array}$

ANNEX II List of Participants 29

ANNEX III List of Papers 32

$\begin{array}{lll}\text { ANNEX IV Summaries of Papers } & 34\end{array}$ 